\title{
On the Current Account - Biofuels Link in Emerging and Developing Countries: Do Oil Price Fluctuations Matter?
}

Gabriel Gomes, Emmanuel Hache, Valérie Mignon \& Anthony Paris

\section{Highlights}

- We show the price impact of biofuels on the current account for agricultural commodity-producing and exporting countries depends on the level reached by the price of oil.

- Positive shocks in the price of biofuels lead to a current-account appreciation for agricultural commodity exporters and producers only when the price of oil is below a certain threshold.

- When the price of oil exceeds this threshold, fluctuations in the price of biofuels no longer affect the current account.

- A rise in the price of oil exerts a negative effect on the trade balance of commodity exporters which are also oil importers, dampening the biofuel price impact on the current-account position. 


\section{Abstract}

Many developed countries promote the use of biofuels for environmental concerns, leading to a rise in the price of agricultural commodities utilized in their production. Such environmental policies have major effects on the economy of emerging and developing countries whose activity is highly dependent on agricultural commodities involved in biofuel production. This paper tackles this issue by examining the price impact of biofuels on the current account for a panel of 16 developing and emerging countries, and the potential nonlinear effect exerted by the price of oil on this relationship. Relying on the estimation of panel smooth-transition regression models, we show that positive shocks in the price of biofuels lead to a current-account appreciation for agricultural commodity exporters and producers only when the price of oil is below a certain threshold. When the price of oil exceeds this threshold, fluctuations in the price of biofuels no longer affect the current account. These findings illustrate that a rise in the price of oil exerts a negative effect on the trade balance of commodity exporters which are also oil importers, dampening the biofuel price impact on the current-account position.

\section{Keywords}

Biofuels, Oil, Current Account, Panel Smooth Transition Regression.

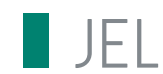

Q16, Q43, F32, C23.

\section{Working Paper}

\section{CEPI}

CEPII (Centre d'Etudes Prospectives et d'Informations Internationales) is a French institute dedicated to producing independent, policyoriented economic research helpful to understand the international economic environment and challenges in the areas of trade policy, competitiveness, macroeconomics, international finance and growth.
CEPII Working Paper

Contributing to research in international economics

C C CEPII, PARIS, 2017

All rights reserved. Opinions expressed in this publication are those of the author(s) alone.

$\begin{array}{ll}\text { Editorial Director: } & \text { CEPII } \\ \text { Sébastien Jean } & \begin{array}{l}\text { 113, rue de Grenelle } \\ 75007 \text { Paris }\end{array} \\ \text { Production: } & +33153685500 \\ \text { Laure Boivin } & \text { www.cepii.fr } \\ \text { No ISSN: } 1293-2574 & \text { Press contact: presse@ }\end{array}$




\title{
On the current account - biofuels link in emerging and developing countries: do oil price fluctuations matter ${ }^{1}$
}

\author{
Gabriel Gomes*, Emmanuel Hache ${ }^{\dagger}$, Valérie Mignon ${ }^{\ddagger}$ and Anthony Paris ${ }^{\S}$
}

\section{Introduction}

For the past two decades, a strong interest has emerged in favor of the integration of renewable energies in the electricity mix and in the transportation sector. This constitutes a major concern for developed economies as well as for developing and emerging countries in order to ensure energy transition policies, to fight against climate change and reduce Greenhouse Gas Emissions. Implementing renewable energies is all the more relevant because they allow the country to earn double dividends, as their diffusion de facto reduces the volume of imported fossil fuels in parallel of environmental objectives (Criqui and Mima, 2012). Along these lines, the use of biofuels is encouraged in developed countries and in emerging economies such as Brazil, ${ }^{2}$ China and India for environmental concerns, as well as for promoting energy security, agricultural opportunities and economic growth. For instance, the European Union introduced a blending target of biofuels in petroleum products in 2003, and the Renewable Fuel Standard program (2005) combined with the Energy Independence and Security act of 2007 (36 billion gallons of biofuels by 2020) allowed the establishment of mandatory target of biofuels utilization in the United States' transportation sector. However, such environmental policies may cause externalities or adverse effects on the economy of emerging and developing countries whose activity is highly dependent on agricultural commodities used in biofuel production. Aiming at investigating those topical issues, this paper analyzes the

\footnotetext{
${ }^{1}$ This research has been supported by the French Energy Council, Paris, France. We would like to thank Anne-Laure Delatte and Sébastien Jean for helpful comments and suggestions.

${ }^{*}$ EconomiX-CNRS, University of Paris Nanterre, France. Email: gabriel.gomes@outlook.fr.

†IFP Energies nouvelles, 1 et 4 avenue de Bois Préau, 92852 Rueil-Malmaison, France. Email: emmanuel.hache@ifpen.fr.

‡EconomiX-CNRS, University of Paris Nanterre and CEPII, France. Corresponding author: Valérie Mignon, EconomiX-CNRS, University of Paris Nanterre, 200 avenue de la République, 92001 Nanterre Cedex, France. Phone: 331409758 60. E-mail: valerie.mignon@u-paris10.fr

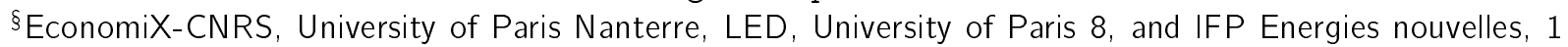
et 4 avenue de Bois Préau, 92852 Rueil-Malmaison, France. Email: anthony.paris@ifpen.fr.

${ }^{2}$ Brazil launched the Proalcool program in 1975 just after the first oil shock. This program triggered an acceleration in the use of ethanol for the transportation sector and innovations on flex-fuel engines for the car industry.
} 
price impact of biofuels on the economy of such countries, focusing on the current account.

These various aforementioned concerns have lead to a sharp rise in biofuel production since the mid-2000s. As shown in Figure 1, while biofuel production was on average around 30 thousand barrels from 2001 to 2005, it started to take off in 2006 with a production that has increased more than ten-fold compared to the beginning of the first half of the 2000s. First-generation biofuels being produced with agricultural commodities (animal fats, starch, sugar and vegetable oil), ${ }^{3}$ this dynamics has been accompanied by an increase in the price of those raw materials (see Figure 1 ). ${ }^{4}$ This rise in the price of agricultural commodities may exert important effects on the current account of emerging and developing countries. Regarding countries exporting agricultural commodities, the effect may be not clear cut at a first sight. Indeed, the direct effect may be positive on the current account if the price increase is sufficient to compensate the potential decrease in the quantity of exported agricultural commodities. However, the commodity price increase is detrimental for domestic consumption which, in turn, negatively affects economic activity and the current account.

By focusing here on the current account, we fall into the spirit of the oil - macroeconomy literature. Indeed, it is well known that oil-exporting countries experiment large current account improvements following a sharp rise in oil prices (see Allegret, Couharde, Coulibaly, and Mignon (2014) and the references therein). In other words, for such countries, oil windfalls constitute a key source of foreign exchange and income. The price of oil is also a key element behind agricultural commodity prices (see Paris (2016) and the references therein, and Figure 1). Shocks in the price of oil spill over agricultural production costs which comprise fertilizer and fuel (Baffes, 2007; Baffes, 2010; Berument, Sahin, and Sahin, 2014), thus decreasing supply. On the consumer side, the impact can be either negative or positive. On the one hand, positive shocks in the price of oil have a negative impact on

\footnotetext{
${ }^{3}$ Typical first-generation biofuels are sugarcane ethanol, starch-based or 'corn' ethanol, biodiesel and Pure Plant Oil (PPO). The feedstock for producing first-generation biofuels either consists of sugar, starch and oil bearing crops or animal fats that, in most cases, can also be used as food and feed or consists of food residues (IEA, 2010).

${ }^{4}$ In particular, the "food versus fuel" debate that followed the large increase in commodity prices in 2007-2008 triggered several articles about co-movements between commodity prices, subsidies policy in the agricultural sector and economic development based on biofuels production policy (see, e.g., Thompson (2012) and the references therein). Moreover, in addition to biofuels, the upward dynamics of agricultural commodity prices during the 2000s comes from a combination of demand and supply shocks. On the demand side, strong economic growth in developing and emerging countries (especially China) has played a positive impact on the global call for commodities (Abbott and Borot de Battisti, 2011; Abbott, Hurt, and Tyner, 2011). On the supply side, adverse local agro-climatic conditions (temperature and precipitation) in major producing countries (OECD, 2008) negatively affected the volume of commodities available in the market.
} 
Figure 1 - Biofuel production, crude oil price and food price index

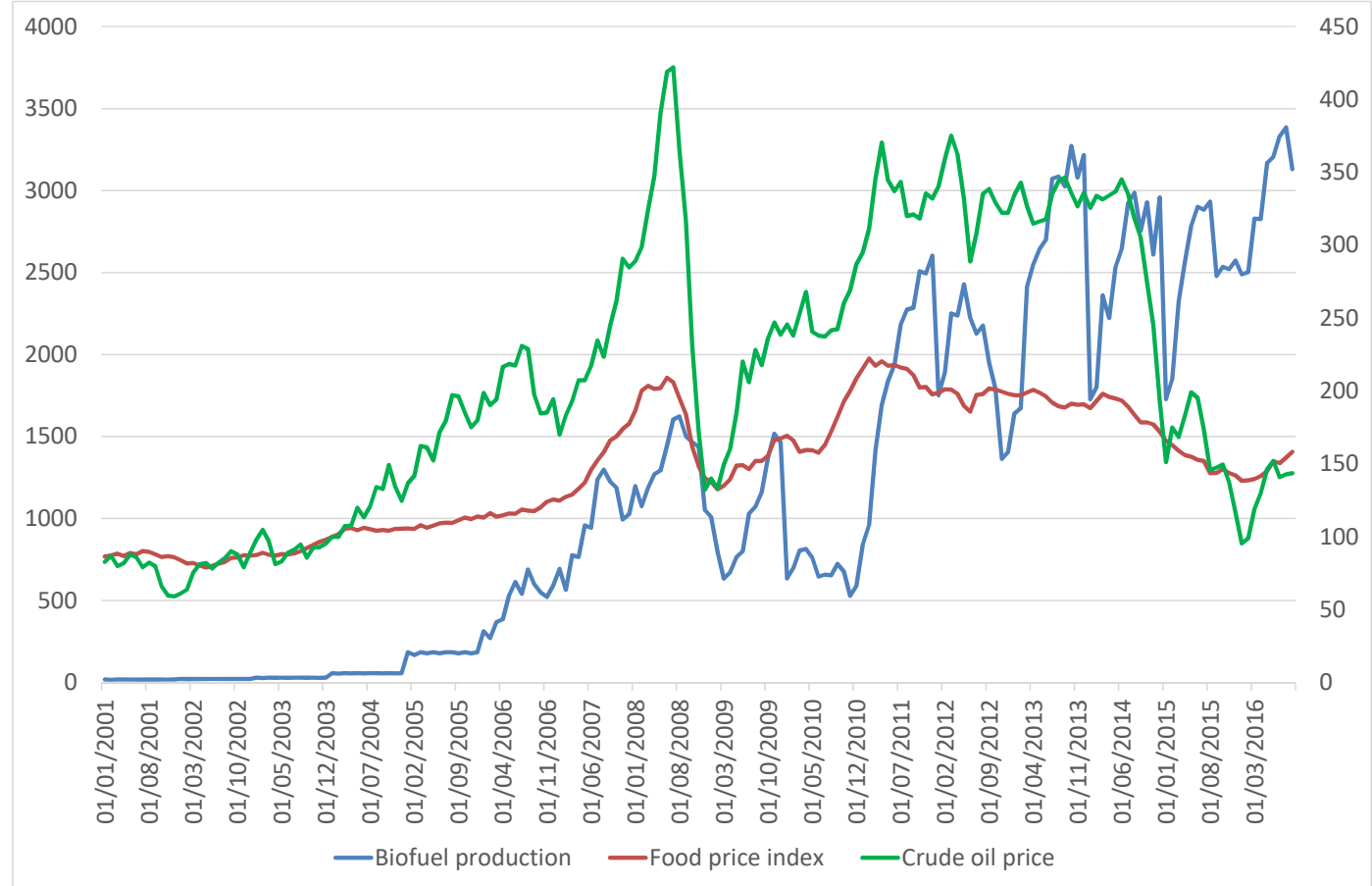

Note: This figure reports the evolution of biofuel production (left-hand scale; source: U.S. Energy Information Administration), crude oil price (simple average of Dated Brent, West Texas Intermediate, and the Dubai Fateh spot prices; right-hand scale; source: IMF) and food price index (right-hand scale; source: FAO) over the January 2001 - September 2016 period at monthly frequency. 
demand if in their food purchasing decisions, households account for price changes in other goods among those oil products (Gohin and Chantret, 2010). In this case, oil and agricultural commodity prices would have a negative relationship. On the other hand, a positive link between agricultural commodity demand and oil prices is likely to occur through the development of biofuels: due to the substitution effect between fuel and biofuel, a rise in the price of oil could lead to an increase in the demand for biofuel (Ciaian and Kancs, 2011). In this context, oil and agricultural commodity prices would be positively related.

The preceding arguments show that important links exist between the price of agricultural raw materials used in biofuel production, the price of oil and the current account of emerging and developing countries exporting or importing agricultural commodities. While the impacts caused by biofuel production development are likely to be highly significant on the economy of such countries, the literature on this topic is very scarce. ${ }^{5}$ This paper aims at filling this gap by examining the price impact of biofuels, through the price of its agricultural inputs, on the current account for a panel of 16 countries - 9 developing and 7 emerging economies - which are either exporters, producers or importers of agricultural commodities used in biofuel production. As stressed above, due to the links existing between the price of agricultural commodities, the price of oil and the current account, the biofuels-current account nexus is likely to depend on the dynamics in the oil market. Indeed, for a country exporting (resp. importing) agricultural commodities used in biofuel production but importing (resp. exporting) crude oil, a high price of oil could strengthen (resp. weaken) the effect of biofuel prices on the current account via the link between oil and agricultural prices. However, this high oil price could affect negatively this biofuel price effect with an increase in the country's import spending for crude oil.

Acknowledging this major role played by the price of oil, we account for such nonlinearities by estimating a panel smooth-transition regression (PSTR) model. In this type of modeling, the price impact of biofuels on the current account varies, depending on the value of another observable variable, i.e., the price of oil. Specifically, the observations in the panel are divided into two homogeneous groups or "regimes" - high oil price and low oil price regimes-, with different coefficients depending on the regimes. Regression coefficients are allowed to change gradually when moving from one group to another: PSTR is a regime-switching

\footnotetext{
${ }^{5}$ Indeed, most of the studies dealing with developing and emerging countries have been concerned with the impact of current and targeted domestic biofuel production on land or agricultural commodities' availability, on water resources required for cultivation and on food prices (see, e.g., Khanna, Onal, Chen, and Huang, 2008; Yang, $\mathrm{Xu}$, Zhang, Hu, Sommerfeld, and Chen, 2011; and Khanna and Crago, 2012). The main exception is Chakravorty, Hubert, and Marchand (2015) who have addressed the impact of US biofuel mandate on poverty in India.
} 
model where the transition from one state to the other is smooth rather than discrete. To our best knowledge, this paper is the first to address the price impact of biofuels on the current account for such countries by accounting for nonlinearities exerted by the price of oil.

Estimating PSTR models over the 2000-2014 period for emerging and developing countries classified into three groups-exporters, producers, importers of agricultural commodities used for biofuel production-our results can be summarized as follows. We show that, overall, a rise in the biofuel price tends to appreciate the current-account position for exporting and producing countries. However, this biofuel price impact is nonlinear, depending on the level reached by the price of oil. For low values of the price of oil, a $10 \%$ increase in the price of biofuels significantly appreciate the current account by around $2 \%$. When the price of oil exceeds the threshold of 56 US dollars per barrel for producers and 45 US dollars for exporters, changes in the price of biofuels no longer impact the current account. These findings indicate that an oil price increase negatively affects the trade balance of agricultural commodity exporters which are also oil importers, dampening the biofuel price impact on the current-account position.

The rest of the paper is organized as follows. Section 2 provides some stylized facts regarding the links between agricultural commodity and oil prices, and their evolution. Section 3 describes the data and methodology. Section 4 presents our findings and Section 5 concludes the paper.

\section{Some stylized facts}

Let us provide a first insight regarding the links between agricultural commodity prices and the price of oil, and their evolution along with the development of biofuel production. To this end, we consider monthly price series ranging from January 1980 to June 2016. All agricultural commodity and oil price series are taken from IMF. ${ }^{6}$ Table 1 reports the correlations of some agricultural commodity price series with the price of oil, all series being expressed in first-logarithmic difference.

As shown, correlations are quite low over the whole period, the highest value being equal to $16 \%$ for palm oil. These results indicate that the links between agricultural commodity and oil prices are not very strong on the full sample. As stressed above, the development of biofuel production has been particularly important since the mid-2000s and not accounting for this dynamics may mask important evolutions in the link between our series of interest.

\footnotetext{
${ }^{6}$ The crude oil price index is the simple average of Dated Brent, West Texas Intermediate, and the Dubai Fateh spot prices.
} 
Table 1 - Correlations between agricultural commodity and oil price series

\begin{tabular}{l|c|c|c|c|c}
\hline \hline & Corn & Wheat & Soybean oil & Palm oil & Sugar cane \\
\hline $1980.02-2016.06$ & 0.0443 & 0.0820 & 0.1331 & 0.1601 & 0.0167 \\
$1980.02-2005.12$ & -0.1146 & -0.0380 & -0.0502 & 0.0277 & 0.0031 \\
$2006.01-2016.06$ & 0.3112 & 0.2437 & 0.5383 & 0.4504 & 0.0829 \\
\hline \hline & Sorghum & Sugar beet & Rapeseed oil & Sunflower oil & \\
\hline $1980.02-2016.06$ & 0.0291 & 0.0404 & 0.0758 & 0.0968 & \\
$1980.02-2005.12$ & -0.0886 & 0.0115 & -0.0458 & -0.0360 & \\
$2006.01-2016.06$ & 0.2260 & 0.1237 & 0.5059 & 0.2819 &
\end{tabular}

Note: This table reports correlations between agricultural commodity and oil price series expressed in first-logarithmic difference. Source: authors' calculations based on IMF data.

Indeed, the rise in biofuel production may have intensified the relation between agricultural commodity and oil prices.

To simply illustrate the hypothesis of a stronger link between agricultural commodities and oil prices since the development of biofuel production, we also calculate the previous correlations over two subperiods, i.e. before and after 2006 as this year corresponds to the date of the major take-off in biofuel production worldwide. As shown in Table 1, correlations over the first subperiod are very weak, and even slightly negative for some commodities. Clearly, the links between agricultural commodities and oil were very tiny. These findings are in sharp contrast with those obtained after 2006. All correlations have strongly increased, the most impressive rises being observed for palm oil, rapeseed oil, and soybean oil.

This preliminary analysis based on correlation coefficients reveals that the links between agricultural commodity prices and the price of oil have sharply increased with the development of biofuel production. To complement this first investigation, Figure 2 reports rolling correlations (calculated for a three-year window) between the price of oil and three agricultural commodity prices, namely soybean oil, palm oil and corn prices (price series being expressed in their first-logarithmic difference). ${ }^{7}$ While these correlations followed a declining trend during the first mid-2000s, the dynamics evolves in the opposite sense after, with values reaching very high levels - this pattern being thus observed for commodities used both for biodiesel and ethanol.

\footnotetext{
${ }^{7}$ The figures for the other commodities considered display similar patterns.
} 
Figure 2 - Rolling correlations

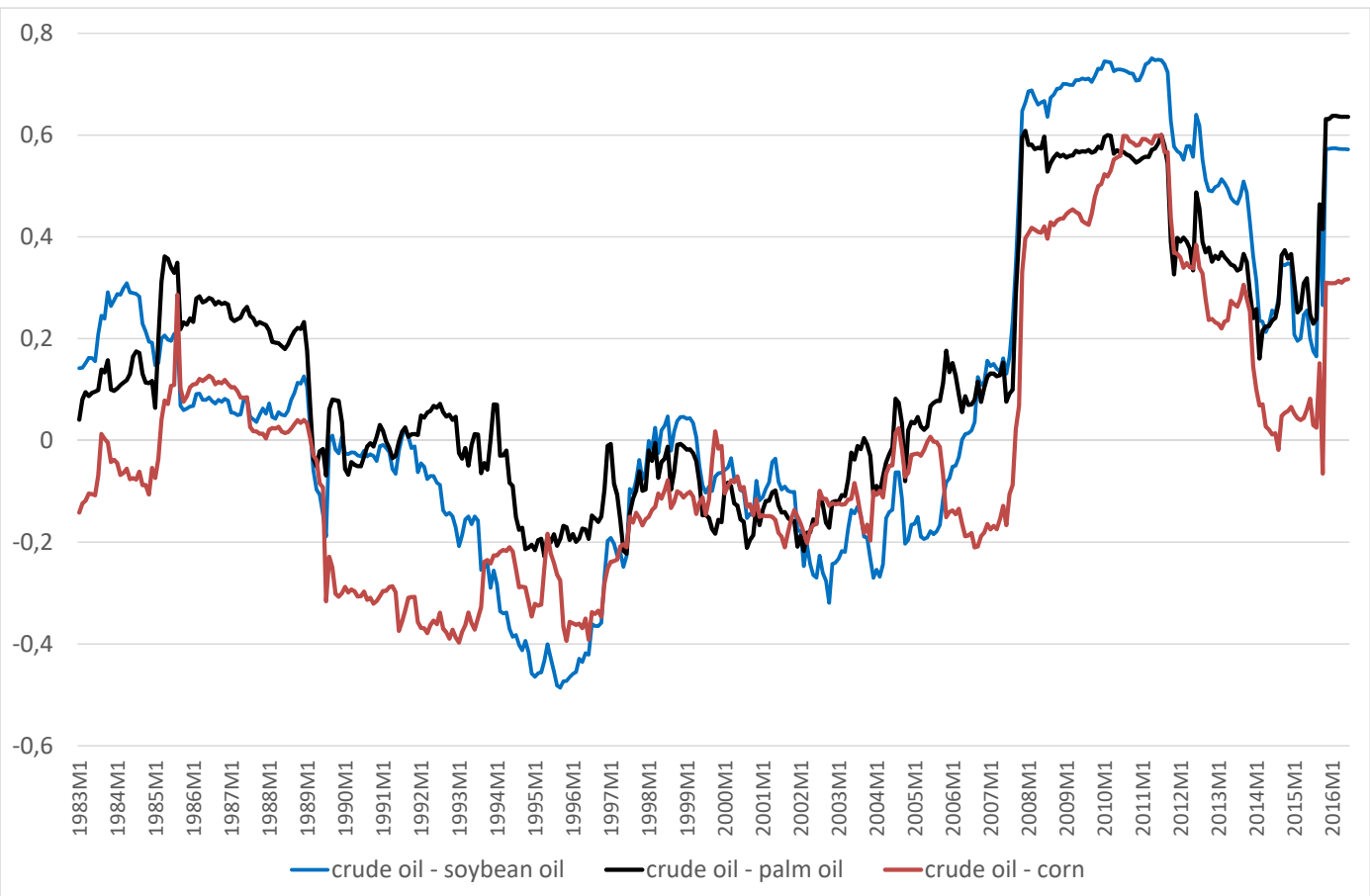

Note: This figure displays three-year rolling correlations between the price of oil and (i) soybean oil price, (ii) palm oil price, and (iii) corn price (expressed in their first-logarithmic difference). Source: authors' calculations based on price data extracted from IMF. 


\section{Data and methodology}

For our estimations, we rely on annual data over the 2000-2014 period. The dependent variable is the current account to GDP ratio, extracted from WDI (World Development Indicators, World Bank). Turning to the explanatory and control variables, we consider usual current-account determinants (see below, subsection 3.2) in addition to our biofuel feedstock price index whose calculation is described below. ${ }^{8}$ As stressed above, we acknowledge that this current account - biofuel price relationship may vary depending on the price of oil. The latter is defined as the simple average (in logarithm) of Dated Brent, West Texas Intermediate and the Dubai Fateh spot prices, and is extracted from IMF (International Financial Statistics, IFS).

\subsection{Aggregated biofuel price and panel of countries}

As first-generation biofuels are produced from agricultural commodities, the first step consists in selecting those raw materials. In a second step, we have to identify for each retained commodity which emerging and developing countries are producer, exporter and importer. This leads us to retain the following 10 commodities used in biofuel production: sugar cane, sugar beet, corn, soybean oil, palm oil, wheat, sorghum, cassava, rapeseed oil, and sunflower oil. ${ }^{9}$ Turning to the panel of countries (see Table 2), we consider as producer (resp. exporter, importer) a country which produces (resp. exports, imports) at least one of the commodities listed above.

From the selected 10 commodities, we construct an aggregate biofuel price index based on the weight of each commodity in the volume of biofuel production. Let us now briefly describe the construction of the biofuel price index.

First, we have to identify the countries which are major players in biofuel production. Based on data from the U.S. Energy Information Administration, we select a sample of 14 countries and regions, representing between $97 \%$ and $100 \%$ of the world ethanol and biodiesel production depending on the considered year. ${ }^{10}$ Second, we rely on annual reports of the U.S. Department of Agriculture (USDA) to specify the quantity of each commodity used in the production of biofuels in each selected country for each year. Third, we aggregate

\footnotetext{
${ }^{8} \mathrm{As}$ (i) the biofuel feedstock price index can be calculated only at the yearly frequency, and (ii) data on the current-account position for our panel of countries are available only at the same frequency, this explains why we use annual data in our empirical analysis.

${ }^{9}$ While emerging and developing countries are not major actors on rapeseed oil and sunflower oil markets, we include those commodities in our analysis as they enter significantly in the biofuel production process.

${ }^{10}$ These countries are the following: Argentina, Australia, Brazil, Canada, China, Colombia, Guatemala, Indonesia, Malaysia, Peru, Philippines, Thailand, United States, and the EU28.
} 
Table 2 - Panel of countries

\begin{tabular}{l|c|c}
\hline \hline Producer & Exporter & Importer \\
\hline Congo & Argentina & Algeria \\
Nigeria & Brazil & Bangladesh \\
Pakistan & China & Egypt \\
Sudan & India & Ethiopia \\
Argentina & Indonesia & Iran \\
Brazil & Mexico & Pakistan \\
China & Thailand & Sudan \\
India & & China \\
Indonesia & & India \\
Mexico & & Indonesia \\
Thailand & & Mexico \\
& & Thailand \\
\hline
\end{tabular}

Note: In italics: developing country; otherwise: emerging country. Emerging: G20 countries or countries in the upper-middle income group classification from the World Bank (GNI per capita between $\$ 4,036$ and $\$ 12,475)$; Developing: otherwise.

these data to determine the total quantity of each agricultural commodity used in the annual production of biofuels at a world level and, in turn, their corresponding share. Fourth, based on these weights, we construct a price index for one ton of agricultural input in the biofuel production. ${ }^{11}$ Finally, we calculate our aggregate price index from these data and the world price of each agricultural commodity - the latter being computed on the basis of the prices of the three main producers of each commodity. ${ }^{12}$ The evolution of this biofuel feedstock price index is displayed on Figure 3.

\subsection{Current-account determinants}

Based on the previous literature, ${ }^{13}$ we rely on the usual current-account determinants: the net foreign asset (NFA) position expressed as percentage of GDP, the ratio of exports plus imports of goods and nonfactor services to GDP as a proxy of openness, dependency ratio

\footnotetext{
${ }^{11}$ As an illustration, one ton of input in 2010 was composed of sugar cane for $69.95 \%$, corn for $24.18 \%$, sugar beet for $1.70 \%$, rapeseed oil for $1.25 \%$, wheat for $1.13 \%$, soybean oil for $1.04 \%$, palm oil for $0.46 \%$, cassava for $0.25 \%$, sunflower oil for $0.026 \%$, and sorghum for $0.024 \%$.

${ }^{12}$ In doing so, we account for disparities in agricultural prices that may be caused by protection of some domestic markets or high transportation costs.

${ }^{13}$ See Calderon, Chong, and Loayza (2002), Chinn and Prasad (2003), Gruber and Kamin (2007), Calderon, Chong, and Zanforlin (2007), Chinn and Ito (2007), Chinn and Ito (2008), Brissimis, Hondroyiannis, Papazoglou, Tsaveas, and Vasardani (2012), Cheung, Furceri, and Rusticelli (2013) and Allegret, Couharde, Coulibaly, and Mignon (2014) among others.
} 
Figure 3 - Biofuel feedstock price index evolution

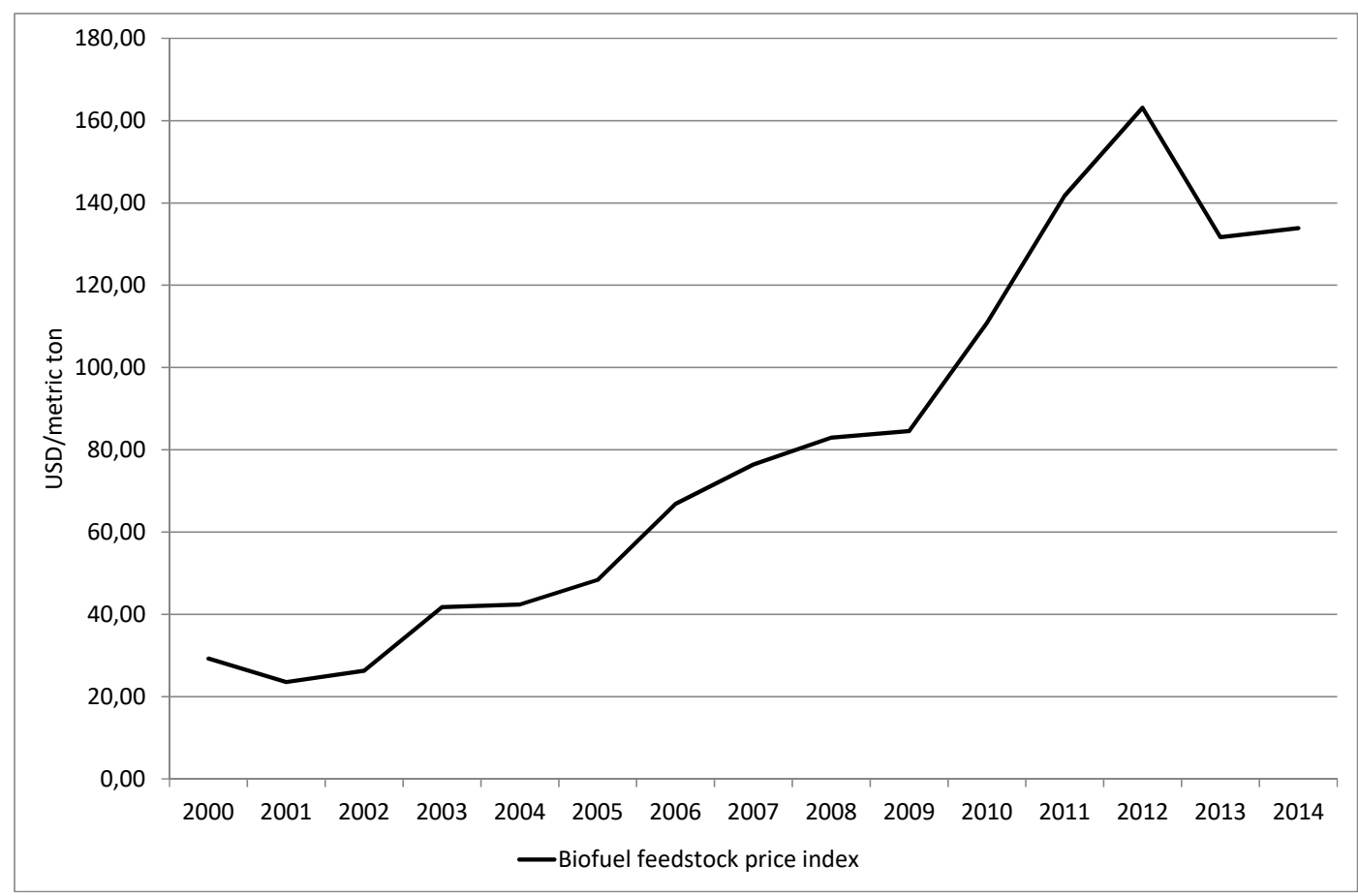

Source: authors' calculations. 
expressed as the ratio of dependent population (below 15 and above 65) to the working age population (between 15 and 64), terms of trade (in logarithm) defined as the ratio of export prices to import prices, GDP per capita, adjusted by PPP exchange rates, relative to the United States, the ratio of M2 to GDP used as an indicator of financial depth, and the population growth rate. All these variables are taken from WDI.

\subsection{PSTR specification}

To assess the potential nonlinear effect exerted by the price of oil on the biofuel price current account relationship, we rely on the PSTR methodology proposed by Gonzalez, Terasvirta, and van Dijk (2005). According to the PSTR specification, current-account regression coefficients are allowed to change across countries and with time, depending on the price of oil. The observations are divided in - say - two regimes delimited by a threshold reached by the oil price, with estimated coefficients that vary depending on the considered regime. The change in the estimated value of coefficients is smooth and gradual, as PSTR models are regime-switching models in which the transition from one state to the other is smooth rather than discrete. Thanks to these specificities, PSTR models allow us to account for sufficient heterogeneity in view of the diversity of our sample of countries.

Let $C A_{i, t}$ denote the current account in percent of GDP in country $i$ at time $t$. The PSTR specification is given by:

$$
C A_{i, t}=\alpha_{i}+\beta_{0} \Delta B_{t}+\beta_{1} \Delta B_{t} \times F\left(P_{t} ; \gamma, c\right)+\phi^{\prime} X_{i, t}+\epsilon_{i, t}
$$

for $i=1, \ldots, N, N$ being the number of countries, and $t=1, \ldots, T . \alpha_{i}$ stands for country fixed effects, $\Delta B_{t}$ denotes the biofuel price index expressed in first logarithmic difference, $P_{t}$ is the price of oil expressed in logarithm that acts as a transition variable, $F$ is a transition function, $X_{i, t}$ is a vector of control variables, and $\epsilon_{i, t}$ is an independent and identically distributed error term. To assess the impact of the price of oil on the biofuel price - current account relationship, we consider that only the biofuel price varies according to the level reached by the price of oil.

The transition function $F$ is bounded between 0 and 1 , and is expressed as:

$$
F\left(P_{t} ; \gamma, c\right)=\left[1+\exp \left(-\gamma \prod_{l=1}^{m}\left(P_{t}-c_{l}\right)\right)\right]^{-1}
$$


$\gamma(\gamma>0)$ denotes the slope parameter and $c_{l}, l=1, \ldots, m\left(c_{1} \leq c_{2} \leq \ldots \leq c_{m}\right)$, are the threshold parameters. From an empirical point of view and as mentioned by Gonzalez, Terasvirta, and van Dijk (2005), it is sufficient to consider only the cases of $m=1$ (logistic) or $m=2$ (quadratic logistic) to capture the nonlinearities due to regime switching. ${ }^{14}$

Depending on the value reached by the price of oil, the link between the current-account position and the biofuel price is given by a continuum of parameters, namely $\beta_{0}$ in the first regime (when $F()=$.0 ) and $\beta_{0}+\beta_{1}$ in the second regime (when $F()=$.1 ). In other words, depending on the level of the price of oil, a biofuel price change has a different effect - that varies across countries and over time-on the current account dynamics.

Following the methodology used in the time series context, Gonzalez, Terasvirta, and van Dijk (2005) suggest a three step strategy to apply PSTR models: (i) specification, (ii) estimation, (iii) evaluation and choice of the number $r$ of regimes. The identification step aims at testing for homogeneity against the PSTR alternative and at selecting (i) between the logistic and logistic quadratic specification of the transition function-i.e., the appropriate order of $m$-and (ii) the transition variable as the one that minimizes the associated $p$-value. Then, if the nonlinearity hypothesis is retained, nonlinear least squares are used in the estimation step to obtain the parameter estimates once the data have been demeaned (see Hansen, 1999; and Gonzalez, Terasvirta, and van Dijk, 2005). Finally, various misspecification tests are applied in the third step to check the validity of the estimated PSTR model and determine the number of regimes $r$.

\section{Results}

We start by testing the linearity hypothesis in Equation (1) using the Gonzalez, Terasvirta, and van Dijk (2005) test with the price of oil (in logarithm) as the transition variable. Results are reported in Table 3 for the following panels of countries whose composition is given in Table 2: the whole panel including our 16 considered countries, the panel of 11 producing countries, the sample of 7 exporting countries, and the panel of 12 importing countries.

Results in Table 3 indicate that the null of linearity is rejected in favor of the alternative of logistic PSTR specification for all panels except importing countries. The latter result

\footnotetext{
${ }^{14}$ Note that the PSTR model can be extended to $r$ regimes, with $r>2$ (see Gonzalez, Terasvirta, and van Dijk, 2005).
} 
Table 3 - Linearity tests (p-values)

\begin{tabular}{l|c|c|c}
\hline \hline & $\mathrm{LM}$ & $\mathrm{F}$ & $\mathrm{LR}$ \\
\hline Whole sample & $0.02^{* *}$ & $0.03^{* *}$ & $0.02^{* *}$ \\
Producing countries & $0.05^{*}$ & $0.08^{*}$ & $0.05^{*}$ \\
Exporting countries & $0.04^{* *}$ & $0.06^{*}$ & $0.04^{* *}$ \\
Importing countries & 0.26 & 0.30 & 0.26 \\
\hline
\end{tabular}

Note: This table reports the results of Lagrange multiplier (LM), F-type $(F)$ and likelihood ratio $(L R)$ tests for linearity. Null hypothesis: linear model. Alternative hypothesis: PSTR model with two regimes $(r=1)$.

$* * *($ resp. $* *, *)$ : rejection of the null hypothesis at the $1 \%($ resp. $5 \%, 10 \%)$ significance level.

regarding importers may be related to the policies implemented in some of those importing economies.

In Asia (China, India, and Indonesia for example), governments introduced specific measures after the 2007-2008 peak in commodity prices in order to protect domestic markets from inflation pressures. In China, a mix of temporary economic tools regarding import tariffs or the cancellation of VAT rebate on exports for specific agricultural products was implemented until 2007 to stabilize the domestic market (Jones and Kwiecinski, 2010). As an illustration, soybeans' import tariff was divided by 3 and the $13 \%$ rebate on ethanol, soybeans and grains exports was eliminated. In India, import tariffs for maize (resp. vegetable oil) reduced from $50 \%$ to zero (resp. $80 \%$ to zero) till 2007 . Indonesia applied the same kind of fiscal tools regarding soybeans (reduction of import tariffs from $10 \%$ to zero) and palm oil (restriction of exports). All those measures could have limited the current-account deterioration with the reduction of international price pressures in the domestic market, thus explaining the absence of nonlinearities on the biofuel price impact on the current account in importing countries. ${ }^{15}$

Table 4 - Transmission of world commodity prices to the domestic market: Elasticity of price transmission (2003-2006 and 2003-2009)

\begin{tabular}{l|c|c}
\hline \hline & $2003-2006$ & $2003-2009$ \\
\hline China, soybean & 0.95 & 0.38 \\
India, soybean & 1.40 & 0.56 \\
Indonesia, wheat & 3.05 & 0.46 \\
\hline \multicolumn{2}{|c}{ Source: Jones and Kwiecinski (2010). }
\end{tabular}

Turning to the three other panels, in the whole sample as well as in commodity-producing ${ }^{15} \mathrm{As}$ illustrated in Table 4, elasticities of international price transmission have indeed strongly decreased across the two considered periods reaching values less than unity. 
and -exporting countries, fluctuations in the price of biofuels impact the current account differently, depending on the level reached by the price of oil. Let us now proceed to the estimation of the PSTR models to investigate this property more deeply.

Table 5 - PSTR estimation

\begin{tabular}{|c|c|c|c|c|c|c|}
\hline & \multicolumn{2}{|c|}{ Whole sample } & \multicolumn{2}{|c|}{ Producing countries } & \multicolumn{2}{|c|}{ Exporting countries } \\
\hline & Regime 1 & Regime 2 & Regime 1 & Regime 2 & Regime 1 & Regime 2 \\
\hline$\Delta B$ & $0.19 * * *$ & $-0.18 * *$ & $0.21^{* *}$ & $-0.20^{*}$ & $0.24^{* * *}$ & $-0.22^{* *}$ \\
\hline$N F A(-1)$ & $-0.12 * * *$ & & -0.01 & & -0.01 & \\
\hline Openness & 0.01 & & 0 & & $-0.11^{*}$ & \\
\hline Dependency & $-0.17^{*}$ & & 0.05 & & 0 & \\
\hline TOT & $0.11^{* * *}$ & & $0.09 *$ & & 0 & \\
\hline$G D P P P P$ & -0.02 & & 0.02 & & -0.05 & \\
\hline$M 2$ & 0.09 & & 0.10 & & -0.05 & \\
\hline$P O P$ & $0.15^{* * *}$ & & $0.13^{* *}$ & & 0.05 & \\
\hline c & \multirow{2}{*}{\multicolumn{2}{|c|}{$\begin{array}{c}4.09(60 \$) \\
5.92\end{array}$}} & \multirow{2}{*}{\multicolumn{2}{|c|}{$\begin{array}{c}4.03(56 \$) \\
7.70\end{array}$}} & \multirow{2}{*}{\multicolumn{2}{|c|}{$\begin{array}{c}3.81(45 \$) \\
3.36\end{array}$}} \\
\hline$\gamma$ & & & & & & \\
\hline
\end{tabular}

Table 5 reports the estimation of our PSTR model (Equation (1)) using the price of oil as the transition variable for the three panels of countries for which the null hypothesis of linearity has been rejected. ${ }^{16}$

Let us first briefly comment the results concerning the control variables. For the whole sample, the effect of (lagged) NFA to GDP ratio (NFA(-1)) on the current account is negative. Countries displaying large net foreign asset positions are able to undergo longlasting trade deficits while remaining solvent. This characteristic may thus explain the negative link between net foreign asset and current-account positions. Population (POP) positively affects the current account, while the dependency ratio has a negative impact. As recalled by Allegret, Couharde, Coulibaly, and Mignon (2014), this result could be related to the life-cycle hypothesis: a rise in the dependency ratio tends to exert a negative effect on aggregate domestic saving, affecting in turn negatively the current-account position.

Consistent with the Harberger-Laursen-Metzler effect (see Bouakez and Kano, 2008), we find that terms of trade (TOT) and current account are positively linked: if income increases

\footnotetext{
${ }^{16}$ To save space, results of the corresponding misspecification tests are not reported, but are available upon request to the authors. All the estimated models displayed in Table 5 have successfully passed the tests (parameter constancy, no remaining heterogeneity).
} 
more than spending following an improvement in terms of trade, the current account will automatically improve. Openness has a negative influence on the current account for exporting countries. Given that our sample of exporters mainly contains emerging countries, this result is in line with those generally obtained in the literature for such economies (Chinn and Prasad, 2003; Cheung, Furceri, and Rusticelli, 2013; and Allegret, Couharde, Coulibaly, and Mignon, 2014). The underlying idea is that openness lifts trade barriers favoring flows of goods and services and foreign direct investments, making those countries more attractive to foreign capital and increasing investment opportunities. Consequently, the relationship between openness and the current account is negatively signed.

It is worth mentioning that GDP per capita, adjusted by PPP exchange rates, relative to the United States (GDP PPP) is never significant. This finding is in accordance with Chinn and Prasad (2003), Cheung, Furceri, and Rusticelli (2013) and Allegret, Couharde, Coulibaly, and Mignon (2014), and can be explained through the stage of economic development of our countries relative to the United States. Indeed, some countries are at early stages of development with a corresponding negative effect on the current account, while others have reached higher levels of development with an associated positive impact on the current-account position. On the whole, the coefficient of the variable is found to be nonsignificant due to the compensation of negative and positive effects. Finally, our findings show that financial depth, proxied by the ratio $M 2 / G D P(M 2)$, has no significant effect on the current-account position. This result is not surprising given our panel of countries, which are economies characterized by a weak developed financial system.

Let us now turn to our main variable of interest, namely the price of biofuels. Our PSTR estimations show that, overall, the current-account position is positively affected by the price of biofuels. ${ }^{17}$ The intensity of such impact is nonlinear, depending on the level reached by the price of oil. For the three samples of countries, when the price of oil is low (Regime 1 ), the biofuel price impact is positive with a coefficient amounting to about 0.20 . In other words, a $10 \%$ increase in the price of biofuels leads to a current-account appreciation of $2 \%$. As expected, this effect is higher and more significant for exporting countries than for producing economies. Indeed, exporters' current account is directly affected by our biofuel price index via the price of agricultural commodities exported. Given the construction of our producers' panel—which mainly includes exporters - we obtain a similar, but weaker effect for this group of countries. The biofuel impact on the current account differs in the second regime. Indeed, in this regime characterized by a price of oil higher than 60

\footnotetext{
${ }^{17}$ It is worth mentioning that we have also estimated our model lagging the price of biofuels. The results (available upon request to the authors) were very similar, highlighting the robustness of our findings to endogeneity issues.
} 
US dollars per barrel for the whole sample, fluctuations in the price of biofuels no longer affect the current-account position. The threshold $c$ after which the price of biofuels has no significant effect varies across groups, being equal to 56 US dollars per barrel for producers and 45 US dollars per barrel for exporters.

A possible explanation for these results is the following. For the group of exporting countries, when the price of oil is low, positive variations in the price of commodities used in biofuel production translate into an improvement in terms of trade which, in turn, positively impact the current account. When the price of oil tends to increase, it exerts a negative impact on the trade balance of exporters which are crude oil importers, therefore weakening the effect exerted by the biofuel price on the current-account position: a rise in the price of oil tends to dampen the biofuel price effect through the increase in the corresponding country's import spending for crude oil (see Table 6 for an illustration).

Table 6 - Oil and petroleum products' balances, in million barrels per day (2004-2014)

\begin{tabular}{l|c|c}
\hline \hline & Oil & Petroleum products \\
\hline Argentina & -0.1121 & -0.0393 \\
Brazil & 0.1473 & 0.2272 \\
China & 4.5562 & 0.4541 \\
India & 2.3620 & -0.6389 \\
Indonesia & 0.4613 & 0.4094 \\
Mexico & -1.1697 & 0.4091 \\
Thailand & 0.6653 & -0.1329
\end{tabular}

Note: This table reports the mean oil balance and the mean petroleum products' balance over the 2004-2014 period. A positive (resp. negative) sign indicates that the concerned country is importer (resp. exporter) over the considered period. Source: ENERDATA.

Turning to the group of producing countries, which comprises oil exporters (such as Mexico, Nigeria, Sudan to name a few), positive variations in the price of biofuels increase the trade-off between biofuel and oil when the price of oil is low. Higher prices of biofuels increase the demand for oil, thus benefiting oil exporters. As a result, the impact on the current account is positive.

Considering finally the whole sample, as it includes both mechanisms, the biofuel price impact on the current account is weakened, and the threshold oil price value is higher.

For the sake of completeness, Figure 4 displays the transition functions. ${ }^{18}$ As shown,

\footnotetext{
${ }^{18}$ It should be mentioned that when representing these functions, the $x$ axis generally reports the values of
} 
Figure 4 - Transition functions

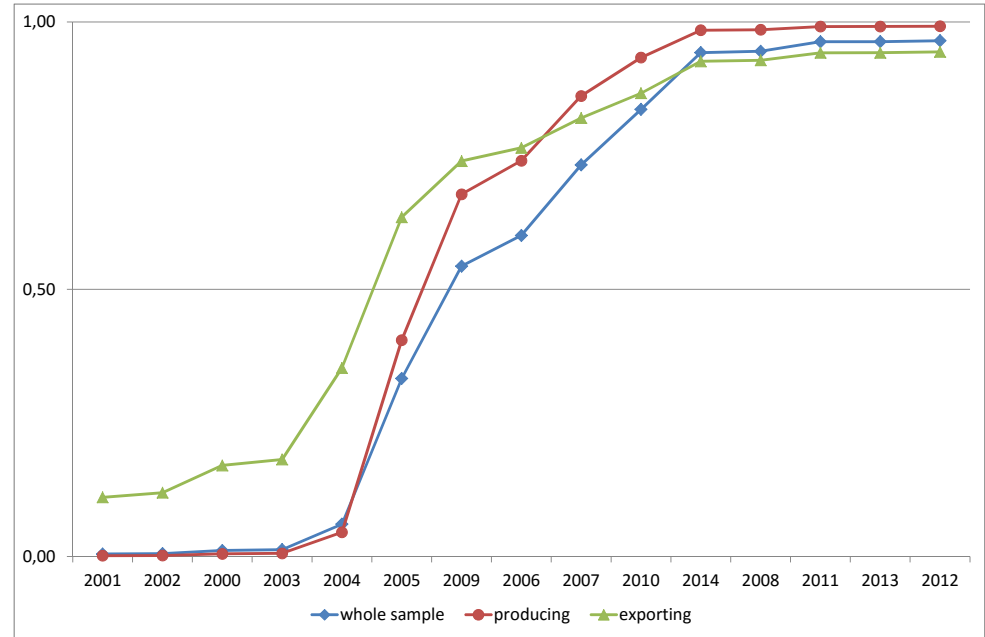

Note: This figure reports the transition function $\left(F\left(P_{t} ; \gamma, c\right)\right)$ associated with each estimated PSTR model for the three groups of countries. Source: authors' calculations.

Regime 2 occurred more often during the covered period, especially for exporting countries. It is worth noticing that, for our three estimated models, Regime 1 corresponds to the 2001-2005 period when biofuel commodities had a low correlation with the price of oil.

\section{Conclusion}

Assessing the impact of fluctuations in the price of biofuels on the economy of emerging and developing countries is worthy of investigation. Indeed, many developed economies promote the use of biofuels for environmental concerns and to ensure energy security, leading a to sharp rise in their production or imports since the mid-2000s. First-generation biofuels being produced from agricultural commodities, this huge increase in biofuel production has been accompanied by an acute rise in the price of those raw materials. As a result, such development of biofuels is likely to generate externalities and adverse effects on the economy of emerging and developing countries whose activity strongly depends on agricultural commodities involved in the biofuel production process.

The present paper tackles this issue by considering a panel of 16 developing and emerging countries which either produce, export or import agricultural commodities used in biofuel the transition variable. Here, the $x$ axis refers to the year of the corresponding values. 
production. Following the oil-macroeconomy literature, we focus on the current-account position of the considered countries as the latter is likely to be affected by the sharp rise in the price of the involved agricultural commodities.

Acknowledging that oil is a key input in agricultural production processes, changes in its price obviously affect agricultural commodities prices. We specifically account for this characteristic by investigating whether the biofuel price-current account relationship depends on the value reached by the price of oil. To this end, we rely on the estimation of a panel smooth-transition regression model in which the biofuel price-current account nexus is allowed to vary depending on whether the price of oil is low or high.

Considering the 2000-2014 period, our findings show that a rise in the biofuel price tends to appreciate the current-account position for agricultural commodity-producing and -exporting countries. However, this impact is nonlinear, depending on the level reached by the price of oil. Specifically, we find that for low values of the price of oil-i.e., below 60 US dollars per barrel for our whole panel of countries-, a 10\% increase in the price of biofuels leads to a significant current-account appreciation of about $2 \%$. When the price of oil increases to exceed 56 US dollars per barrel for producers and 45 US dollars for exporters, fluctuations in the price of biofuels no more significantly affect the current account. These findings illustrate that a rise in the price of oil exerts a negative effect on the trade balance of commodity exporters which are also oil importers, dampening the biofuel price impact on the current-account position.

On the whole, our findings put forward the importance of accounting for the effect of the price of oil in designing policies to promote the use of biofuels. In particular, while an increase in the biofuel price is benefit for commodity-exporting countries in a low oil price regime, it is no more the case in high oil price states. With regard to the "food versus fuel" debate, sharp increase in the price of biofuels coupled with strong rise in the price of oil are likely to exert important detrimental effects on the economy of agricultural commodity-exporting countries.

\section{References}

Abbott, P., and A. Borot de Battisti (2011): "Recent Global Food Price Shocks: Causes, Consequences and Lessons for African Governments and Donors," Journal of African Economies, 20, i12-i62. 
Abbott, P. C., C. Hurt, and W. E. Tyner (2011): "What's Driving Food Prices in 2011?," Issue Reports 112927, Farm Foundation.

Allegret, J.-P., C. Couharde, D. Coulibaly, and V. Mignon (2014): "Current accounts and oil price fluctuations in oil-exporting countries: The role of financial development," Journal of International Money and Finance, 47(C), 185-201.

Baffes, J. (2007): "Oil spills on other commodities," Resources Policy, 32(3), 126 - 134.

(2010): "More on the energy/nonenergy price link," Applied Economics Letters, 17(16), 1555-1558.

Berument, M. H., A. Sahin, and S. Sahin (2014): “The relative effects of crude oil price and exchange rate on petroleum product prices: Evidence from a set of Northern Mediterranean countries," Economic Modelling, 42(C), 243-249.

Bouakez, H., and T. Kano (2008): "Terms of trade and current account fluctuations: The Harberger-Laursen-Metzler effect revisited," Journal of Macroeconomics, 30(1), 260 281.

Brissimis, S., G. Hondroyiannis, C. Papazoglou, N. Tsaveas, and M. Vasardani (2012): "Current account determinants and external sustainability in periods of structural change," Economic Change and Restructuring, 45(1), 71-95.

Calderon, C., A. Chong, and N. Loayza (2002): "Determinants of Current Account Deficits in Developing Countries," The B.E. Journal of Macroeconomics, 2(1), 1-33.

Calderon, C., A. Chong, and L. Zanforlin (2007): "Current Account Deficits in Africa: Stylized Facts and Basic Determinants," Economic Development and Cultural Change, 56, 191-221.

Chakravorty, U., M.-H. Hubert, and B. U. Marchand (2015): "Food for Fuel: The Effect of the U.S. Biofuel Mandate on Poverty in India," Discussion paper.

Cheung, C., D. Furceri, and E. Rusticelli (2013): "Structural and Cyclical Factors behind Current Account Balances," Review of International Economics, 21(5), 923-944.

Chinn, M. D., and H. Ito (2007): "Current account balances, financial development and institutions: Assaying the world "saving glut"," Journal of International Money and Finance, 26(4), 546 - 569, Financial Globalization and Integration.

(2008): "Global Current Account Imbalances: American Fiscal Policy versus East Asian Savings," Review of International Economics, 16(3), 479-498.

Chinn, M. D., and E. S. Prasad (2003): "Medium-term determinants of current accounts in industrial and developing countries: an empirical exploration," Journal of International Economics, 59(1), 47-76.

Ciaian, P., and d. Kancs (2011): "Interdependencies in the energy-bioenergy-food price systems: A cointegration analysis," Resource and Energy Economics, 33(1), 326-348. 
Criqui, P., and S. Mima (2012): "European climate-energy security nexus: A model based scenario analysis," Energy Policy, 41, 827 - 842, Modeling Transport (Energy) Demand and Policies.

Gohin, A., and F. Chantret (2010): "The long-run impact of energy prices on world agricultural markets: The role of macro-economic linkages," Energy Policy, 38(1), 333-339.

Gonzalez, A., T. Terasvirta, and D. van Dijk (2005): “Panel Smooth Transition Regression Models," Research Paper Series 165, Quantitative Finance Research Centre, University of Technology, Sydney.

Gruber, J. W., and S. B. Kamin (2007): "Explaining the global pattern of current account imbalances," Journal of International Money and Finance, 26(4), 500 - 522, Financial Globalization and Integration.

Hansen, B. E. (1999): “Threshold effects in non-dynamic panels: Estimation, testing, and inference," Journal of Econometrics, 93(2), 345-368.

IEA (2010): "Sustainable Production of Second Generation Biofuels," Discussion paper.

Jones, D., and A. Kwiecinski (2010): "Policy Responses in Emerging Economies to International Agricultural Commodity Price Surges," OECD Food, Agriculture and Fisheries Papers 34, OECD Publishing.

Khanna, M., and C. L. Crago (2012): "Measuring Indirect Land Use Change with Biofuels: Implications for Policy," Annual Review of Resource Economics, 4(1), 161-184.

Khanna, M., H. Onal, X. Chen, and H. Huang (2008): "Meeting Biofuels Targets: Implications for Land Use, Greenhouse Gas Emissions and Nitrogen Use in Illinois," Discussion paper.

OECD (2008): "Rising Food Prices: Causes and Consequences," Policy brief, Organisation for Economic Co-operation and Development.

Paris, A. (2016): "The Effect of Biofuels on the Link between Oil and Agricultural Commodity Prices: A Smooth Transition Cointegration Approach," EconomiX Working Papers 2016-5, University of Paris West - Nanterre la Défense, EconomiX.

Thompson, P. B. (2012): "The Agricultural Ethics of Biofuels: The Food vs. Fuel Debate," Agriculture, 2(4), 339-358.

Yang, J., M. Xu, X. Zhang, Q. Hu, M. Sommerfeld, and Y. Chen (2011): "Life-cycle analysis on biodiesel production from microalgae: Water footprint and nutrients balance," Bioresource Technology, 102(1), 159 - 165, Special Issue: Biofuels - II: Algal Biofuels and Microbial Fuel Cells. 